\title{
Lip Repositioning Surgery: A Newer Paradigm in Periodontal Aesthetics
}

\author{
Dr. Manoj Humagain, ${ }^{1}$ Dr. Asmita Dawadi ${ }^{1}$ \\ ${ }^{1}$ Department of Periodontology and Oral Implantology, \\ Kathmandu University School of Medical Sciences, Dhulikhel, Nepal.
}

\begin{abstract}
Periodontal plastic or aesthetic surgery by its definition comprises of surgical procedures performed to correct or eliminate anatomic, developmental or traumatic deformities of the gingiva or oral mucosa. 'Perfect smile' has been the common desire of many people in this era. Smile has significant role in the expression, appearance and in the development of self-esteem. Excessive gingival display, which is commonly termed as 'gummy smile' will adversely affects smile aesthetics and is therefore undesirable to many people. It is one of the several developmental or acquired deformities and conditions that manifest in the periodontium. Different literature reveals common consensus on considering gingival display of greater than $3 \mathrm{~mm}$ is gummy smile and is unaesthetic. Lip repositioning surgery has been establishing as a promising less invasive alternative treatment modality in aesthetic rehabilitation for the cases of excessive gingival display. Perseverance and application of such technique shall provide many more a horizon to this young but highly imaginative and creative technique in periodontal therapy to charter.
\end{abstract}

Keywords: Excessive gingival display; gummy smile; lip repositioning; periodontal aesthetics; treatment modalities.

\section{INTRODUCTION}

The evolution of dentistry over time has brought about increased awareness and demand for enhanced aesthetics. Periodontal aesthetics serves as new portal for clinicians to achieve the same. Periodontal plastic surgery abiding by its definition comprises of surgical procedures performed to correct or eliminate anatomic, developmental or traumatic deformities of the gingiva or oral mucosa.

Intervention within these realms necessitates a systematic aesthetic evaluation including patients request for aesthetic therapy, medical history, and extra-oral evaluation; including facial symmetry, facial dimensions, lip length and thickness, profile and smile line. These are of paramount significance, as mere intra oral procedures alone may not provide satisfactory results in cases where orthognathic and cosmetic surgical procedures may be warranted.

Intraoral examination for gingival symmetry, excessive gingival display (EGD), non scalloped gingival contours,

\section{Correspondence:}

Dr. Manoj Humagain

Department of Periodontology and Oral Implantology, Kathmandu University School of Medical Sciences, Dhulikhel, Nepal. email:mhumagain@gmail.com

\section{Citation}

Humagain M, Dawadi A, Lip Repositioning Surgery: A Newer Paradigm in Periodontal Aesthetics. J Nepal Soc Perio Oral Implantol. 2018;2(1):20-2. open interproximal spaces and gingival recession along with radiographic examination should be carried out in tandem.

'Perfect smile' has been the common desire of many people in this era. ${ }^{1}$ Smile has significant role in the expression, appearance and in the development of self-esteem. Most of the dental practitioners are focused more on dental aesthetics. However, position of the lips, gingival contour and zenith, and the pink and white tissue ratio exposure in the smile will determine the ultimate facial aesthetics. ${ }^{2,3}$

Excessive gingival display (EGD), which is commonly termed as 'gummy smile' will adversely affects smile aesthetics and is therefore undesirable to many people. It is one of the several developmental or acquired deformities and conditions that manifest in the periodontium. ${ }^{4}$ Altered passive eruption, vertical maxillary excess, short or hypermobile upper lip or the combination of these factors are the common etiologies of excessive gingival display. ${ }^{5-7}$

Exposure of pink gingiva of 1.5 to $2 \mathrm{~mm}$ during normal smile is considered as normal while exposure beyond this is termed as excessive gingival display ${ }^{8}$ that can be major cause of patient embarrassment. It has the prevalence rate of $7 \%$ in male and $14 \%$ in female worldwide. ${ }^{9}$ However the amount of gingival display that is considered unaesthetic varies between individuals and the clinicians. Different literature reveals common consensus on considering gingival display of greater than $3 \mathrm{~mm}$ is gummy smile and is unaesthetic. 


\section{Treatment Modalities for Gummy Smile}

Excessive gingival display may be attributed to maxillary overgrowth, tooth malposition, altered passive eruption and, short and hyperactive upper lip. Most of the dentoalveolar causes of EGD like short clinical crown, altered passive eruption, gingival hypertrophy and dentoalveolar extrusion can be corrected by simple restorative and periodontal approach. Surgical crown lengthening, orthodontic treatment, orthognathic surgery, botox injection and surgical lip repositioning are the different treatment modalities that has been used in the treatment of excessive gingival display or gummy smile. Surgical crown lengthening is best option when there is gingival hypertrophy or there short clinical crown due to altered passive eruption. However, surgical crown lengthening in maxillary overgrowth case can lead into un- aesthetic long crowns in the maxillary anterior. Orthognathic surgery is the treatment of choice for the maxillary overgrowth. However, cost, invasiveness and the post-operative morbidity of this technique cannot be justified with the treatment outcomes in minor vertical discrepancy. Botox injection in management of the gummy smile has brought the new horizon of non-surgical and more conservative treatment option in the case of EGD. However, cases treated with Botox injection has the maximum relapse tendency within 3 to 6 months. ${ }^{10,11}$

Surgical management of the EGD due to short and hyperactive upper lip includes lip elongation associatedwith rhinoplasty, ${ }^{12}$ detachment of lip muscles, ${ }^{13}$ myotomy, ${ }^{14}$ and lip repositioning. ${ }^{15,} 16$ Lip repositioning technique was first described by Rubinstein and Kostianovsky ${ }^{17}$ to treat gummy smile in the year 1973. This technique has been proposed as a conservative permanent surgical technique that offers a less invasive approach to EGD as compared to other surgical modalities. ${ }^{18}$

\section{Lip Repositioning Surgery: Clinical and Patient Outcome}

Lip repositioning technique was first published in plastic surgery literature in $1973 .{ }^{17}$ Patient undergoing lip repositioning surgery should be healthy, with no periodontal disease. It should be performed under infiltration of adequate amount of local anesthesia from maxillary right first molar to left first molar. Then the incision area is marked by sterile pencil on dry mucosa. First Incision should be given along the mucogingival junction and second incision will be given almost parallel to the first incision at labial mucosa about 10$12 \mathrm{~mm}$ away from the mucogingival junction. Two incisions will be connected at the first molars of either side with elliptical outline. ${ }^{16}$ The epithelium from the incision outline should be removed by split thickness flap with the exposure of connective tissue bed. Then the two incision line should be approximated by either interrupted or continuous suture.

Most of the published articles on the lip repositioning surgery has reported satisfactory results, however there is limited information in the Dental literature with definite quantifiable outcomes. Most of the literature published were the case reports, showing definite benefits of this technique. Abdullah et $\mathrm{al}^{19}$ did the clinical trial of lip repositioning surgery on 12 patients and found the satisfactory results in 10 cases out of 12 . He found complete relapse in one case after three months. A study done by Kostianovsky and Rubinstein ${ }^{20}$ on 92 patients reported some recurrence in a few patients. Silva et $\mathrm{al}^{15}$ treated a series of 13 patients in Brazilian population with the lip repositioning surgery. In their study, the baseline gingival display was reported to be $5.8 \pm 2.1 \mathrm{~mm}$ which was reduced to $1.4 \pm 1.0 \mathrm{~mm}$ and 1.3 $\pm 1.6 \mathrm{~mm}$ at 3 and 6 months postoperatively respectively. They reported significant reductions in gingival display at 3 months $(4.7 \mathrm{~mm})$ and 6 months $(4.5 \mathrm{~mm})$ postoperatively. A study done by Gabric et $\mathrm{al}^{21}$ concludes that lip repositioning surgery combined with gingivectomy could be used as a minimally invasive alternative to orthognathic surgery for cases of EGD with a complex etiology.

This technique has been described as less invasive and more conservative in many reports. ${ }^{14-16,21}$ Minor postoperative side effects including swelling, bruising, and discomfort are commonly reported. ${ }^{16}$ Some patients report a feeling of tension of the lip for the first postoperative week. ${ }^{19,21,22}$ One article has reported the formation of a mucocele due to the damaging of minor salivary glands during the surgery. ${ }^{23}$ Paresthesia and transient paralysis have also been reported as possible complications. ${ }^{23}$

The psychological scales suggest an improvement in quality of life, a greater well-being, improved subjective aesthetics and a decrease in social appearance anxiety following the lip repositioning procedure. ${ }^{18}$ These outcomes suggest that lip repositioning surgery results are stable after 6 months and are perceived positively by patients undergoing the procedure. $^{18}$

Some studies has reported the high level of satisfaction in patients with lip repositioning surgery. ${ }^{15,}{ }^{24}$ In a study done by Roy ${ }^{25}$ most patients were "very satisfied" or "extremely satisfied" with the amount of gum showing when smiling and considered the amount of gum showing to be "about right" six months after the lip repositioning procedure. After having the overall experience, most patients said they "probably would" or "definitely would" choose to have the procedure again. ${ }^{25}$ As this procedure aims to correct 
the shorter lip causing gummy smile, many author has mentioned upper labial fullness can be achieved after lip repositioning surgery with the significant increase in lip length and vermilion length. ${ }^{25-27}$ A study by Jacono et al found statistically significant increase in upper lip fullness which was associated with a $75 \%$ increase in the vermilion height and a 66\% increase in area of lip. ${ }^{27}$

Lip repositioning is a very simple, easy to perform, short procedure that requires readily available armamentarium and results in fast healing and a significant positive outcome..$^{28,29}$ A systematic review on lip repositioning surgery consider it as successful approach for the treatment of EGD. However, this review warrants crucial need for further clinical trials to reach more conclusive and results regarding the outcome and stability of this treatment approach. ${ }^{17}$

\section{Summary}

In day and age when cosmetics commands equal ground as with therapeutics, periodontal aesthetics is a broad panorama of insightful and innovative techniques aimed at achieving the elusive goal of perfect soft tissue orientation to hard tissue component. Lip repositioning surgery has been establishing as a promising less invasive alternative treatment modality in aesthetic rehabilitation for the cases of excessive gingival display. Long term success and stable periodontal success is the most awaited panorama in this new but less invasive periodontal aesthetic procedure.

\section{REFERENCES}

1. Donitza A. Creating the perfect smile: prosthetic considerations and procedures for optimal dentofacial esthetics. J Calif Dent Assoc. 2008;36(5):335-40.

2. Rokaya D, Kitisubkanchana J, Wonglamsam A, Santiwong P, Srithavaj T, Humagain M. Nepalese Esthetic Dental (NED) Proportion in Nepalese population. Kathmandu Univ Med J (KUMJ). 2015;13 (51):244-9.

3. Humagain M, Rokaya D, Srii R, Dixit S, Kafle D. Gender based comparison of gingival zenith esthetics. Kathmandu Univ Med J (KUMJ) 2016;14(54):148-52.

4. Armitage GC. Development of a classification system for periodontal disease and conditions. Ann Periodontol. 1999;4:1-6.

5. Bynum J. Treatment of a "Gummy Smile”: Understanding etiology is key to success. Compend Contin Educ Dent. 2016;37(2):114-22.

6. Gibson MP, Tatakis DN. Treatment of gummy smile of multifactorial etiology: A case report. J Periodontol. 2017;7(4):167-73.

7. Silberberg N, Goldstein M, Smidt A. Excessive gingival display--etiology, diagnosis, and treatment modalities. Quint Int. 2009;40:809-18.

8. Robbins JW. Differential diagnosis and treatment of excess gingival display. Pract Period Aesthet Dent. 1999;11(2):265-72.

9. Tjan AH, Miller GD, The J G. Some esthetic factors in a smile. J Prosthet Dent. 1984;51(1): 24-8.

10. Jankovic J, Brin MF. Botulinum toxin: historical perspective and potential new indications. Muscle Nerve Suppl. 1997;6:S129-45.

11. Polo M. Botulinum toxin type A in the treatment of excessive gingival display. Am J Orthod Dentofacial Orthop. 2005;127:214.

12. Ezquerra F, Berrazueata MJ, Ruiz-Capillas A, Arregui JS. New approach to the gummy smile. Plast Reconstruct Surg. 1999;104:1143-52.

13. Litton C, Fournier P. Simple surgical correction of gummy smile. Plast Reconstruct Surg. 1979;63:372-5.

14. Ishida LH, Ishida LC, Ishida J. Myotomy of the levator labii superioris muscle and lip repositioning: A combined approach for the correction of gummy smile. Plast Reconstruct Surg. 2010;126:1014-9.

15. Silva CO, Ribeiro-Junior NV, Campos TV. Excessive gingival display: Treatment by a modified lip repositioning technique. J Clin Periodontol. 2013;40:260-8.

16. Simon Z, Rosenblatt A, Dorfman W. Eliminating gummy smile with surgical lip repositioning. J Cosmet Dent. 2014;23:100-8.

17. Rubinstein AM, Kostianovsky AS. Cirugiaestetica de la malformacion de la sonrisa. Prensa Medica Argentina. 1973;60:952.

18. Tawfik K O, El-Nahass E H, Shipman P, Looney W S, Cutler W C, Brunner M. Lip repositioning for the treatment of excess gingival display: A systematic review. J Esthet Restor Dent. 2017;00:1-12.

19. Abdullah W A, Khalil H S, Alhindi M M, Marzook H. Modifying gummy smile: a minimally invasive approach. J Contemp Dent Pract. 2014;15:821-6.

20. Kostianovsky AS, Rubinstein AM. The "Unpleasant” smile. Aesthetic plast surg 1976;1:161-6.

21. Gabric P D, Blaskovic M, Brojovic J, Susic M. Surgical treatment of excessive gingival display using lip repositioning technique and laser gingivectomy as an alternative to orthognathic surgery. J Oral Maxillofac Surg. 2014;72(2): 4041-51.

22. Al Nashar A, Yhya A, Soliaman H. Lip repositioning technique for the reduction of excessive gummy smile: Mini review and case report. Int J Cur Med Pharm Res. 2016;2(10):870-2.

23. Rosenblatt A, Simon Z. Lip repositioning for reduction of excessive gingival display: a clinical report. Int J Periodontics Restorative Dent. 2006;26:433-7.

24. Rao AG, Koganti VP, Prabhakar AK, Soni S. Modified lip repositioning: A surgical approach to treat the gummy smile. J Indian Soc Periodontol. 2015;19:356-9.

25. Roy MB. Lip Repositioning: Patient outcome assessment. Thesis Submitted. Available Online at https://etd.ohiolink.edu/!etd.send_file ?accession=osu $1466520904 \&$ disposition=inline

26. Jacobs PJ, Jacobs BP. Lip repositioning with reversible trial for the management ofexcessive gingival display: a case series. Int J Periodontics Restorative Dent. 2013;33:169-75.

27. Jacono AA, Quatela VC. Quantitative analysis of lip appearance after V-Y lipaugmentation. Arch Facial Plast Surg. 2004;6:172-7.

28. Ozturan S, Ay E, Sagir S. Case series in laser assisted treatment of excessive gingival display: an alternative treatment. Photomed Laser Surg. 2014;32(9):517-23.

29. Dayakar MM, Gupta S, Shivananda H. Lip repositioning: an alternative cosmetic treatment for gummy smile. J Indian Soc Periodontol. 2014;18(4):520-3. 